\title{
Effect of ingested human antibodies induced by RTS, S/AS01 malaria vaccination in children on Plasmodium falciparum oocyst formation and sporogony in mosquitoes
}

Kazutoyo Miura ${ }^{1 *}$, Erik Jongert ${ }^{2}$, Bingbing Deng ${ }^{1}$, Luwen Zhou' ${ }^{1}$, John P Lusingu ${ }^{3,4}$, Chris J Drakeley ${ }^{5}$, Michael P Fay ${ }^{6}$, Carole A Long ${ }^{1}$ and Johan Vekemans ${ }^{2}$

\begin{abstract}
Background: The circumsporozoite protein (CS protein) on the malaria parasites in mosquitoes plays an important role in sporogony in mosquitoes. The RTS,S/AS01 malaria vaccine candidate, which has shown significant efficacy against clinical malaria in a large Phase 3 trial, targets the Plasmodium falciparum CS protein, but the ability of serum from vaccinated individuals to inhibit sporogony in mosquitoes has not been evaluated.

Methods: Previously a double-blind, randomized trial of RTS,S/AS01 vaccine, as compared with rabies vaccine, in five- to 17-month old children in Tanzania was conducted. In this study, polyclonal human antibodies were purified from the pools of sera taken one month after the third vaccination. IgGs were purified from four pools of sera from 25 RTS,S/AS01 vaccinated children each, and two pools of sera from 25 children vaccinated with rabies vaccine each. The ability of antibodies to inhibit $P$. falciparum oocyst formation and/or sporogony in the mosquito host was evaluated by a standard membrane-feeding assay. The test antibodies were fed on day 0 (at the same time as the gametocyte feed), or on days 3 or 6 (serial-feed experiments). The oocyst and sporozoite counts were performed on days 8 and 16, respectively. In addition, two human anti-CS monoclonal antibodies (mAb) and a control mAb were also evaluated.

Results: Polyclonal anti-CS IgG preparations from RTS,S-vaccinated children tested at concentrations of 149-210 ELISA units (EU)/ml did not show significant inhibition in oocyst and sporozoite formation when the antibodies were fed with gametocytes at the same time, or later (serial-feed experiments). Similarly, anti-CS mAbs tested at 6,421 or $7,122 \mathrm{EU} / \mathrm{ml}$ did not show reduction in oocyst and sporozoite formation.

Conclusions: This study does not support the concept that anti-CS antibodies induced by the RTS,S/AS01 vaccines in humans noticeably reduce malaria transmission by blocking $P$. falciparum sporozoite development or salivary gland invasion in mosquitoes when taken up during feeding.
\end{abstract}

Keywords: RTS,S/AS01, Oocyst formation, Sporogony, Standard membrane feeding assay

\footnotetext{
* Correspondence: kmiura@niaid.nih.gov

'Laboratory of Malaria and Vector Research, National Institute of Allergy and Infectious Diseases, National Institutes of Health, 12735 Twinbrook Parkway, Rockville, MD 20852, USA

Full list of author information is available at the end of the article
} 


\section{Background}

There are two ways malaria vaccines could prevent transmission of malaria from one immunized individual to another susceptible individual. One is through the induction of pre-erythrocytic or blood-stage immunity that prevent (or dramatically reduces) gametocyte formation in humans, and the other one is through the induction of immunity that acts in the mosquito to prevent parasites from reaching the salivary glands. The latter strategy relies on the activity of immune effectors ingested with the blood meal against parasite and mosquito antigens that are exposed to the blood meal [1-4].

The RTS,S/AS01 malaria candidate vaccine is being developed with the aim of reducing the clinical disease associated with Plasmodium falciparum malaria in children in Africa when administered to infants and/or young children. While the vaccine has shown a significant efficacy with respect to clinical malaria in a Phase 3 trial [5], the ability of RTS,S/AS01 to reduce malaria transmission has not been evaluated. The RTS,S/AS01 vaccine target antigen is the circumsporozoite protein (CS protein), a 412 amino acids protein abundantly associated with the sporozoite surface. CS protein, the expression of which starts in the oocyst [6-8], plays an important role in sporogony $[9,10]$.

Modelling studies have been conducted, and clinical studies are being considered, to evaluate the potential for RTS,S/AS01, if used in mass vaccination programmes achieving high population coverage, to reduce transmission of malaria through the ability of pre-erythrocytic immunity to reduce incidence of new infection [11]. In contrast, this study evaluates the potential for serum from RTS,S/AS01 immunized children, when ingested by the mosquito with a blood meal, to inhibit sporogony in mosquitoes. The rationale for testing this hypothesis comes from two observations. First, it is known that antibodies ingested by the mosquito during a blood meal can traverse the midgut epithelium and reach the haemolymph [12]. Secondly, it has been demonstrated that mosquitoes infected with transgenic fungi which expressed single light chain anti-CS antibody showed fewer sporozoites in the salivary glands compared to the mosquitoes infected with the wild type fungi [13]. In addition, a recent study indirectly supports the idea of transmission blocking by an anti-CS antibody: antibodies against circumsporozoite protein-binding protein (CSPBP) significantly reduced the sporozoite load in salivary glands of Plasmodium berghei infected mosquitoes [14]. It is, therefore, possible that anti-CS antibodies induced by RTS,S/AS01 vaccination and ingested by the mosquito during a blood meal may affect oocyst formation and/or sporogony in the mosquito host. Past attempts at evaluating the effect of antisporozoite sera on sporogony have led to conflicting results [12,15-18]. This is the first study to evaluate the effect of serum samples from children who were immunized with a vaccine against CS protein.

In this study, the ability of antibodies from children vaccinated with RTS,S/AS01 to inhibit oocyst formation and/or sporogony in the mosquito host was tested using a standard membrane-feeding assay (SMFA). The postvaccination sera collected in a double-blind, randomized trial of RTS,S/AS01 vaccine as compared with rabies vaccine in five- to 17 -month old children in Korogwe, Tanzania were used. The clinical study showed that RTS,S/ AS01 provided a 53\% (95\% confidence interval (CI), 28 to 69; $\mathrm{P}<0.001)$ protection against malaria over an average eight-month period [19]. In the current study, in vitro cultured $P$. falciparum gametocytes were mixed with test antibodies and fed to laboratory-reared Anopheles mosquitoes. After a few days, mosquitoes were dissected and successful progression of the parasite cycle was evaluated by counting oocysts on the midgut basal lamina, or sporozoites in the salivary glands, depending on the numbers of days passed after the infectious feeding. In addition, serial feedings were used, where mosquitoes were first fed on gametocytes without antibodies and then later fed on test antibodies. These serial feedings mimic the fact that in nature mosquitoes feed repeatedly. In addition, human monoclonal antibodies (mAb) against CS [20] were also evaluated.

\section{Methods}

\section{Clinical trial and antibody sample preparation}

A Phase 2b clinical trial of RTS,S/AS01 vaccine (GlaxoSmithKline (GSK) Biologicals, Belgium) was conducted in children in Korogwe, Tanzania, as part of a multicentre, observer-blinded, randomized, controlled trial reported previously [19]. The study was prospectively registered at ClinicalTrials.gov (NCT00380393) and approved by the Tanzanian Medical Research Coordinating Committee, and the Western Institutional Review Board in Seattle. The study was overseen by an Independent Data Monitoring Committee and local safety monitors, and conducted in accordance with the Helsinki Declaration of 1964 (revised 1996) and Good Clinical Practice guidelines. Written informed consent was obtained from the parent or guardian of each child. In brief, children between five and 17 months of age at the time of first vaccination received either RTS,S/AS01 vaccine or a control rabies vaccine, intramuscularly at zero, one and two months.

Because of the small volume of sera available from each child, the current study was based on six serum pools. Each pool was made using sera from 25 vaccinated subjects bled at one month post-third vaccine dose. Four pools were made from children who received RTS,S/AS01 vaccines, and the other two pools were from rabiesimmunized children.

The human anti-RTS, S monoclonal antibodies targeting the repeat region of the CS protein (mAb, MAL1C 
and MAL2A) were generated as described previously [20]. As a control, a malaria-unrelated human mAb was used for each assay.

\section{Anti-CS ELISA}

Anti-CS IgG concentration in each sample was measured using a validated anti-CS ELISA as described previously [20]. The anti-CS IgG concentration is expressed as ELISA units per milliliter $(\mathrm{EU} / \mathrm{ml})$.

\section{IgG purification and standard membrane-feeding assay (SMFA)}

IgG from pooled serum samples were purified via Protein G affinity chromatography (Pierce, Rockford, IL, USA) according to the manufacturer's instructions and adjusted to a final concentration of $20 \mathrm{mg} / \mathrm{ml}$ in phosphate buffered saline (PBS). Four total IgGs from the RTS,S/AS01 group are designated as CS-1, $-2,-3$ and -4 , and two IgGs from the control (rabies) group are designated as Contl- 1 and -2 in this study.

The standardized methodology for performing the SMFA has been described previously [21]. Briefly, 16-18 day old gametocyte cultures of the $P$. falciparum NF54 line $(200 \mu \mathrm{l}$ of $50 \%$ haematocrit culture adjusted to 0.15 $0.2 \%$ stage $\mathrm{V}$ gametocytaemia) were mixed with $60 \mu \mathrm{l}$ of a test sample, and the final mixture was immediately fed to $~ 50$ female Anopheles stephensi (Nijmegen strain, three to six days old) mosquitoes through a membrane-feeding apparatus. The human serum and red blood cells used for the cultures were purchased from Interstate Blood Bank, Inc, Memphis, TN, USA. The polyclonal IgGs were tested at $3.75 \mathrm{mg} / \mathrm{ml}$ of total IgG concentration. For the $\mathrm{mAb}$, the concentration of $0.231 \mathrm{mg} / \mathrm{ml}$ was used. The level of anti-CS specific antibody of each sample (either polyclonal or monoclonal antibodies) in a test feeder was calculated based on EU/ml value of the stock IgG and the dilution factor to make the final mixture for a feeding experiment. For example, CS- 1 sample showed $805 \mathrm{EU} / \mathrm{ml}$ in the stock IgG (at $20 \mathrm{mg} / \mathrm{ml}$ of total IgG), and the antiCS IgG level was calculated as $151 \mathrm{EU} / \mathrm{ml}$ in a test feeder (at $3.75 \mathrm{mg} / \mathrm{ml}$ of total IgG). Mosquitoes were kept for eight days and dissected (20 mosquitoes per sample) to enumerate oocysts in their midguts. Only midguts from mosquitoes with any eggs at the time of dissection were analysed.

For the sporozoite count, mosquitoes were kept for 16 days and dissected to collect salivary glands (12 mosquitoes per sample). The salivary glands from an individual mosquito were transferred to a tube containing $50 \mu \mathrm{l}$ of PBS, then homogenized gently by repeated pipetting. Twenty $\mu \mathrm{l}$ of suspension were transferred to a haemocytometer and the number of sporozoites was determined under a phase-contrast microscope.
For a serial-feed experiment, $\sim 50$ female An. stephensi were fed gametocyte cultures as in a regular SMFA, but without any test antibody, on day $0(100 \mu \mathrm{l}$ infected erythrocytes and $160 \mu \mathrm{l}$ normal human serum). On days 3 or 6 , the mosquitoes were fed again with a test antibody and $50 \%$ haematocrit of uninfected erythrocytes $(60 \mu \mathrm{l}$ test antibody diluted in PBS was mixed with $100 \mu \mathrm{l}$ uninfected erythrocytes and $100 \mu \mathrm{l}$ normal human serum). The final protein concentration of a test IgG in a feeder was the same as a regular SMFA: $3.75 \mathrm{mg} / \mathrm{ml}$ for polyclonal IgGs and $0.231 \mathrm{mg} / \mathrm{ml}$ for mAbs. The oocyst and sporozoite counts were performed on days 8 and 16 post-infectious feed, respectively. In these experiments, salivary glands from 12 mosquitoes for each test sample were pooled in $300 \mu \mathrm{l}$ PBS for counting.

\section{Statistical analysis}

Per cent (\%) inhibition of mean oocyst intensity (PIm[o]) was calculated as: $100 \times\{1$ - (mean number of oocysts in the test group)/(mean number of oocysts in the control groups)\}. Similarly,\% inhibition of mean sporozoite intensity $(\mathrm{PIm}[\mathrm{s}])$ was calculated. For the calculations, an arithmetic mean was used, instead of geometric mean or median, because previous work on oocyst intensity has shown a zero inflated negative binomial distribution fits very well to the data [21]. Other studies also utilized similar negative binomial models for the oocyst data [22,23]. For sporozoite intensity, a study has shown that the log sporozoite intensity is approximately linearly related to the log oocyst intensity [24] in the case of P. falciparum infection in Anopheles gambiae mosquitoes. Therefore, it seems like a reasonable assumption to use arithmetic means for sporozoite analyses as well. The\% inhibition of oocyst prevalence $(\mathrm{PIp}[\mathrm{o}])$ was evaluated as: $100 \times\{1-$ (proportion of mosquitoes with any oocysts in the test group)/(proportion of mosquitoes with any oocyst in the control group)\}. The lowest number of sporozoite detected by this method (the haemocytometer measurement described above) was $3 \times 10^{3}$ per mosquito. Therefore, the mosquito with 'zero' sporozoites might have some sporozoites $\left(<3 \times 10^{3}\right)$ if they were examined with a more sensitive method. For this reason,\% inhibition of sporozoite prevalence was not analysed in this study. For estimating the PIm[s] and its CI, the value of $1.5 \times 10^{3}$ (the half of the minimum non-zero count in the current study) was assigned for a mosquito with 'zero' sporozoites.

The CI for PIm[o] of each test sample was calculated using a zero-inflated negative binomial random effects model which was similar to the method described previously [21]. For this study the zero-inflation factor and the random effects standard errors for the container of mosquitoes (COM, viz, a group of mosquitoes which were housed in the same container and were fed the same culture and test antibodies) and feeds were estimated from 
the previous study [21]. Under the model, new data (in which means were obtained from the current study) were simulated and the middle $95 \%$ was used as the CI. For the CI of PIp[o] and PIm[s], it was not possible to use the same model as the historical data were not sufficient (in case of PIp[o]) or no such data were available (PIm[s]). Therefore, the method of Miettinen and Nurminen [25] was used for PIp[o] and the negative binomial method for $\operatorname{PIm}[\mathrm{s}]$. Both methods did not account for the random effect for COM and feeds, as there were no data to estimate those effects, and hence the results will tend to be anti-conservative, ie, reject more often than the nominal 0.05 level.

For the polyclonal IgG data, a meta regression model was used to compare $\operatorname{PIm}[\mathrm{o}]$ values between anti-CS IgGs (four samples) and control IgGs (two samples). The same model was utilized to compare PIm[s] values of the two groups for the regular feed. Since the sporozoite counts were done with pools of salivary glands of 12 mosquitoes per group in the serial-feed experiments, a $t$-test was used to compare the PIm[s] data. The PIp[o] data of two groups were compared by a logistic regression allowing for over-dispersion.

To combine the data from two independent feeding experiments, a normal fixed effects meta analysis method on the log relative risks was used. The metaphor $\mathrm{R}$ package was used for the analysis [26].

All statistical tests were performed in R (version 2.15.2) and two-sided $\mathrm{p}$-values $<0.05$ were considered significant.

\section{Results}

Transmission-blocking activity of IgGs from human sera of RTS,S-vaccinated children

The purified total IgGs of CS-1, $-2,-3$ and -4 (at $3.75 \mathrm{mg} / \mathrm{ml}$ ) corresponded to anti-CS concentrations of 151, 210, 149 and $156 \mathrm{EU} / \mathrm{ml}$, respectively, while control IgGs, Contl-1 and -2, showed less than $0.1 \mathrm{EU} / \mathrm{ml}$. The concentrations of anti-CS antibodies (149-210 EU/ml) were lower than levels observed at peak (one month post dose 3, geometric mean of $539.6 \mathrm{EU} / \mathrm{ml}$ [19]), but higher than that observed a few months later $(71.9 \mathrm{EU} / \mathrm{ml} 1.5$ to 7.5 (mean of 5) months after the peak) [19], and similar to peak levels in young infants $(199.9 \mathrm{EU} / \mathrm{ml})$ [27] and in 1-4 years old children (207 EU/ml) [28].

Table 1 shows\% inhibition (and the CI) of mean oocyst intensity $(\mathrm{PIm}[\mathrm{o}])$, oocyst prevalence (PIp[o]), and mean sporozoite intensity (PIm[s]) of each anti-CS IgG compared to the Control IgGs. Since there were huge variations in oocyst and sporozoite numbers even within the same COM, the estimates of\% inhibition had large CIs (Table 1). Therefore, four anti-CS IgGs and two control IgGs were compared as groups. In terms of the oocyst intensity, the model estimated that the mean in the antiCS IgG group was $1.0(95 \% \mathrm{CI},-2.7$ to $4.7 ; \mathrm{p}=0.59)$ higher than that in the control. The odds ratio of oocyst prevalence in anti-CS IgG group compared to control was estimated as 2.7 (95\% CI, 0.7 to $10.7 ; \mathrm{p}=0.15)$. For the sporozoite intensity, the model estimated the mean in anti-CS IgG group was $1.6 \times 10^{3}(95 \% \mathrm{CI},-2.9$ to $\left.6.2 \times 10^{3} ; \mathrm{p}=0.48\right)$ higher. Taken together, there was no significant inhibition in anti-CS IgGs compared to the control IgGs for any readouts.

Since CS protein is only synthesized six days or later after a gametocyte feed in a mosquito [9], a serial-feed experiment, where the same mosquitoes were fed again with test antibodies on days 3 or 6 after gametocyte feed, was performed. The inhibitory activities of each individual test IgG are shown in Table 2 (day 3 serial feed) and Table 3 (day 6 serial feed). Similar to the regular feed (Table 1), the variations in the oocyst numbers were large. Therefore, the effect of anti-CS IgG was also evaluated as a group. For the oocyst intensity, the mean in the anti-CS IgG group was $2.7(95 \% \mathrm{CI},-6.2$ to $11.6 ; \mathrm{p}=0.55)$ or 2.2 (95\% CI, -3.9 to $8.3 ; \mathrm{p}=0.48$ ) higher than those in control in the day 3 or 6 serial feeds, respectively. The odds ratio of oocyst prevalence in the anti-CS IgG group compared to control was 0.32 ( $95 \% \mathrm{CI}, 0.02$ to $6.0 ; \mathrm{p}=0.49)$ in the day 3 serial feed. In the day 6 serial feed, since only one mosquito (who was fed with CS-2) with zero oocysts (all other mosquitoes in both groups had more than one oocyst), no comparison was performed for the prevalence data. For the sporozoite numbers, there was no significant difference between the two groups ( $p=0.34$ for day 3 serial feed, and $\mathrm{p}=0.43$ for day 6 serial feed).

\section{Transmission-blocking activity of human monoclonal anti-CS antibodies}

Two human monoclonal antibodies (MAL1C and MAL2A) were also evaluated in this study. Using the mAb, it was possible to test at higher CS-specific antibody concentration in the membrane-feeding assay. The anti-CS specific antibody levels of MAL1C and MAL2A were 7,122 and $6,421 \mathrm{EU} / \mathrm{ml}$ when they were tested at $0.231 \mathrm{mg} / \mathrm{ml}$ protein concentration.

In the first experiment with mAb, MAL1C, MAL2A and control (Contl) $\mathrm{mAb}$ were fed along with the gametocyte culture. While MAL1C mAb did not show any inhibition, MAL2A showed $61 \%$ inhibition ( $95 \% \mathrm{CI},-24$ to 87 ; $\mathrm{p}=0.089)$ in oocyst intensity (PIm[o]) and $32 \%$ inhibition ( $95 \% \mathrm{CI}, 7$ to $55 ; \mathrm{p}=0.018$ ) in oocyst prevalence (PIp[o]) in the first feeding experiment (Table 4). A second experiment was performed to confirm this inhibitory activity, but here, MAL2A did not show any inhibition. When the data from the two feeding experiments were combined, MAL2A showed 21\% inhibition (95\% CI, -73 to 64; $\mathrm{p}=0.551)$ in $\mathrm{PIm}[\mathrm{o}]$ and $7 \%$ inhibition $(95 \% \mathrm{CI},-9$ to 21 ; $\mathrm{p}=0.361)$ in PIp[o]. The $2 \mathrm{mAbs}$ did not show any inhibition in sporozoite counts (Table 4). 
Table 1 Transmission-blocking activities of human polyclonal lgGs fed with infected blood meal ${ }^{\mathrm{a}}$

\begin{tabular}{|c|c|c|c|c|c|c|c|c|c|}
\hline Sample & Mean ooc ${ }^{b}$ & $\mathrm{PIm}[\mathrm{o}]^{\mathrm{c}}$ & p-value ${ }^{d}$ & Mosquito $^{\mathrm{e}}$ & PIp [o] ${ }^{f}$ & p-value ${ }^{g}$ & Mean Spz & $\operatorname{PIm}[s]^{i}$ & $p$-value ${ }^{j}$ \\
\hline \multirow[t]{2}{*}{$\mathrm{CS}-1$} & 10.7 & 4 & 0.87 & $1 / 20$ & -9 & 0.36 & 14.8 & -51 & 0.32 \\
\hline & $(0,34)$ & $(-142,64)$ & & & $(-30,14)$ & & $(0,52.3)$ & $(-257,31)$ & \\
\hline \multirow[t]{2}{*}{ CS-2 } & 10.8 & 3 & 0.88 & $1 / 20$ & -9 & 0.36 & 15.3 & -56 & 0.29 \\
\hline & $(0,20)$ & $(-134,65)$ & & & $(-30,14)$ & & $(0,43.0)$ & $(-274,30)$ & \\
\hline \multirow[t]{2}{*}{$\mathrm{CS}-3$} & 12.2 & -9 & 0.95 & $1 / 20$ & -9 & 0.36 & 10.1 & -3 & 0.94 \\
\hline & $(0,38)$ & $(-174,59)$ & & & $(-30,14)$ & & $(0,19.3)$ & $(-152,54)$ & \\
\hline \multirow[t]{2}{*}{ CS-4 } & 14.2 & -27 & 0.67 & $1 / 20$ & -9 & 0.36 & 9.1 & 6 & 0.89 \\
\hline & $(0,26)$ & $(-208,53)$ & & & $(-30,14)$ & & $(0,41.3)$ & $(-150,61)$ & \\
\hline \multirow[t]{2}{*}{ Contl-1 } & 10.6 & N/A & N/A & $2 / 20$ & N/A & N/A & 8.9 & N/A & N/A \\
\hline & $(0,49)$ & & & & & & $(0,22.8)$ & & \\
\hline \multirow[t]{2}{*}{ Contl-2 } & 11.7 & N/A & N/A & $3 / 20$ & N/A & N/A & 10.6 & N/A & N/A \\
\hline & $(0,34)$ & & & & & & $(0,25.3)$ & & \\
\hline
\end{tabular}

${ }^{\mathrm{a}}$ All purified $\mathrm{lgGs}$ were tested at $3.75 \mathrm{mg} / \mathrm{ml}$ and fed with infected blood meal at the same time.

${ }^{\mathrm{b}}$ Arithmetic mean (range) of oocysts per mosquito midgut.

${ }^{c}$ Per cent inhibition of mean oocyst intensity (PIm[o]) and the $95 \%$ confidence interval $(95 \% \mathrm{Cl})$.

${ }^{\mathrm{d}}$ Two-sided p-values for testing whether PIm[o] is significantly different from 0 .

${ }^{\mathrm{e}}$ Number of mosquitoes without any oocysts/number of mosquitoes examined.

f Per cent inhibition of prevalence of mosquitoes with oocysts (Plp[o]) and the $95 \% \mathrm{Cl}$.

${ }^{\mathrm{g} p}$-values of PIp[o].

${ }^{\mathrm{h}}$ Arithmetic mean (range) of sporozoites $\left(\times 10^{3}\right)$ per mosquito.

'Per cent inhibition of mean sporozoite intensity (PIm[s]) and the $95 \% \mathrm{Cl}$.

${ }_{\mathrm{j}}^{\mathrm{j}}$-values of PIm[s].

Serial-feed experiments were also performed with the $\mathrm{mAb}$, similar to the polyclonal antibodies, on days 3 (Table 5) or 6 (Table 6) after gametocyte feed. Neither of the mAb showed significant inhibition in oocyst intensity (PIm[o]) or oocyst prevalence (PIp[o]) in both experiments.
For the inhibition in sporozoite intensity (PIm[s]), the inhibitory activity of MAL1C was not consistent (53 and $-129 \%$ inhibitions in the day 3 and 6 serial feeds, respectively), and MAL2A mAb did not show any inhibition in both serial-feeds.

Table 2 Transmission-blocking activities of human polyclonal IgGs fed three days post-infected blood meal ${ }^{\mathrm{a}}$

\begin{tabular}{|c|c|c|c|c|c|c|c|c|}
\hline Sample & Mean ooc $^{\mathbf{b}}$ & $\operatorname{PIm}[0]^{c}$ & $p$-value ${ }^{d}$ & Mosquito $^{\mathrm{e}}$ & PIp[o] ${ }^{f}$ & $p$-value ${ }^{g}$ & Mean Spz & $\operatorname{PIm}[s]^{i}$ \\
\hline \multirow[t]{2}{*}{ CS-1 } & 30.0 & 1 & 0.93 & $3 / 20$ & 13 & 0.07 & 71.3 & -184 \\
\hline & $(0,75)$ & $(-148,62)$ & & & $(-1,35)$ & & & \\
\hline \multirow[t]{2}{*}{ CS-2 } & 29.9 & 1 & 0.92 & $0 / 20$ & -3 & 0.48 & 49.4 & -97 \\
\hline & $(2,56)$ & $(-139,62)$ & & & $(-15,14)$ & & & \\
\hline \multirow[t]{2}{*}{$\mathrm{CS}-3$} & 37.6 & -24 & 0.66 & $0 / 20$ & -3 & 0.48 & 56.9 & -127 \\
\hline & $(5,69)$ & $(-190,51)$ & & & $(-15,14)$ & & & \\
\hline \multirow[t]{2}{*}{ CS-4 } & 34.5 & -14 & 0.88 & $3 / 20$ & 13 & 0.07 & 35.4 & -41 \\
\hline & $(0,87)$ & $(-175,57)$ & & & $(-1,35)$ & & & \\
\hline \multirow[t]{2}{*}{ Contl-1 } & 25.5 & $\mathrm{~N} / \mathrm{A}$ & $\mathrm{N} / \mathrm{A}$ & $0 / 20$ & $\mathrm{~N} / \mathrm{A}$ & $\mathrm{N} / \mathrm{A}$ & 43.1 & $\mathrm{~N} / \mathrm{A}$ \\
\hline & $(1,80)$ & & & & & & & \\
\hline \multirow[t]{2}{*}{ Contl-2 } & 35.0 & $\mathrm{~N} / \mathrm{A}$ & $\mathrm{N} / \mathrm{A}$ & $1 / 20$ & $\mathrm{~N} / \mathrm{A}$ & $\mathrm{N} / \mathrm{A}$ & 7.0 & $\mathrm{~N} / \mathrm{A}$ \\
\hline & $(0,83)$ & & & & & & & \\
\hline
\end{tabular}

${ }^{a}$ All purified lgGs were tested at $3.75 \mathrm{mg} / \mathrm{ml}$ and fed three days post-infected blood meal.

${ }^{\mathrm{b}}$ Arithmetic mean (range) of oocysts per mosquito midgut.

${ }^{c}$ Per cent inhibition of mean oocyst intensity (PIm[o]) and the $95 \%$ confidence interval $(95 \% \mathrm{Cl})$.

${ }^{\mathrm{d}}$ Two-sided $\mathrm{p}$-values for testing whether PIm[o] is significantly different from 0.

e Number of mosquitoes without any oocysts/number of mosquitoes examined.

f Per cent inhibition of prevalence of mosquitoes with oocysts (Plp[o]) and the $95 \% \mathrm{Cl}$.

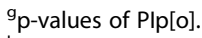

${ }^{h}$ Number of sporozoites $\left(\times 10^{3}\right)$ per mosquito calculated from a pool of salivary glands of 12 mosquitoes.

'Per cent inhibition of mean sporozoite intensity (PIm[s]) calculated with the average of sporozoites counts of Contl-1 and Contl-2. 
Table 3 Transmission-blocking activities of human polyclonal IgGs fed six days post-infected blood meal ${ }^{\mathrm{a}}$

\begin{tabular}{|c|c|c|c|c|c|c|c|c|}
\hline Sample & Mean ooc ${ }^{b}$ & $\operatorname{PIm}[0]^{c}$ & $p$-value ${ }^{d}$ & Mosquito $^{\mathrm{e}}$ & PIp[o] ${ }^{f}$ & p-value ${ }^{g}$ & Mean Spz & $\operatorname{PIm}[s]^{i}$ \\
\hline \multirow[t]{2}{*}{ CS-1 } & 37.7 & -13 & 0.82 & $0 / 20$ & 0 & 1.00 & 91.1 & -2 \\
\hline & $(19,82)$ & $(-176,54)$ & & & $(-10,16)$ & & & \\
\hline \multirow[t]{2}{*}{ CS-2 } & 33.7 & -1 & 0.97 & $1 / 20$ & 5 & 0.15 & 72.7 & 19 \\
\hline & $(0,54)$ & $(-151,63)$ & & & $(-4,24)$ & & & \\
\hline \multirow[t]{2}{*}{ CS-3 } & 35.8 & -8 & 0.94 & $0 / 20$ & 0 & 1.00 & 87.4 & 3 \\
\hline & $(5,72)$ & $(-157,59)$ & & & $(-10,16)$ & & & \\
\hline \multirow[t]{2}{*}{ CS-4 } & 34.6 & -4 & 0.98 & $0 / 20$ & 0 & 1.00 & 83.8 & 7 \\
\hline & $(6,74)$ & $(-144,61)$ & & & $(-10,16)$ & & & \\
\hline \multirow[t]{2}{*}{ Contl-1 } & 33.2 & N/A & N/A & $0 / 20$ & N/A & N/A & 84.8 & N/A \\
\hline & $(10,62)$ & & & & & & & \\
\hline \multirow[t]{2}{*}{ Contl-2 } & 33.3 & N/A & N/A & $0 / 20$ & N/A & N/A & 94.7 & N/A \\
\hline & $(10,77)$ & & & & & & & \\
\hline
\end{tabular}

${ }^{a}$ All purified lgGs were tested at $3.75 \mathrm{mg} / \mathrm{ml}$ and fed six days post-infected blood meal.

${ }^{\mathrm{b}}$ Arithmetic mean (range) of oocysts per mosquito midgut.

${ }^{c}$ Per cent inhibition of mean oocyst intensity (PIm[o]) and the $95 \%$ confidence interval $(95 \% \mathrm{Cl})$.

${ }^{\mathrm{d}}$ Two-sided p-values for testing whether PIm[o] is significantly different from 0 .

${ }^{\mathrm{e}}$ Number of mosquitoes without any oocysts/number of mosquitoes examined.

f Per cent inhibition of prevalence of mosquitoes with oocysts (Plp[o]) and the $95 \% \mathrm{Cl}$.

${ }^{\mathrm{g} p}$-values of PIp[o].

${ }^{\mathrm{h}}$ Number of sporozoites $\left(\times 10^{3}\right)$ per mosquito calculated from a pool of salivary glands of 12 mosquitoes.

'Per cent inhibition of mean sporozoite intensity (PIm[s]) calculated with the average of sporozoites counts of Contl-1 and Contl-2.

Table 4 Transmission-blocking activities of human mAb fed with infected blood meal ${ }^{\mathrm{a}}$

\begin{tabular}{|c|c|c|c|c|c|c|c|c|c|}
\hline Sample & Mean ooc ${ }^{b}$ & $\mathrm{PIm}[0]^{\mathrm{c}}$ & p-value ${ }^{d}$ & Mosquito $^{\mathrm{e}}$ & PIp [o] ${ }^{f}$ & p-value ${ }^{g}$ & Mean Spz ${ }^{\mathrm{h}}$ & $\operatorname{PIm}[s]^{i}$ & p-value \\
\hline \multicolumn{10}{|c|}{ First experiment } \\
\hline \multirow[t]{2}{*}{ MAL1C } & 18.8 & 3 & 0.94 & $3 / 20$ & 11 & 0.29 & 37.9 & -21 & 0.72 \\
\hline & $(0,55)$ & $(-191,67)$ & & & $(-14,33)$ & & $(0,94.0)$ & $(-254,58)$ & \\
\hline \multirow[t]{2}{*}{ MAL2A } & 7.5 & 61 & 0.09 & $7 / 20$ & 32 & 0.02 & 39.0 & -24 & 0.63 \\
\hline & $(0,37)$ & $(-24,87)$ & & & $(7,55)$ & & $(0.5,89.0)$ & $(-215,51)$ & \\
\hline \multirow[t]{2}{*}{ Contl } & 19.5 & N/A & N/A & $1 / 20$ & N/A & $\mathrm{N} / \mathrm{A}$ & 31.2 & $\mathrm{~N} / \mathrm{A}$ & N/A \\
\hline & $(0,36)$ & & & & & & $(0,146.5)$ & & \\
\hline \multicolumn{10}{|c|}{ Second experiment } \\
\hline \multirow[t]{2}{*}{ MAL1C } & 33.8 & -21 & 0.71 & $0 / 20$ & 0 & 1.000 & N.D. & N.D. & N.D. \\
\hline & $(12,59)$ & $(-248,56)$ & & & $(-19,16)$ & & & & \\
\hline \multirow[t]{2}{*}{ MAL2A } & 42.2 & -51 & 0.46 & $0 / 20$ & 0 & 1.000 & N.D. & N.D. & N.D. \\
\hline & $(13,71)$ & $(-344,49)$ & & & $(-19,16)$ & & & & \\
\hline \multirow[t]{2}{*}{ Contl } & 27.9 & N/A & N/A & $0 / 20$ & N/A & N/A & N.D. & N.D. & N.D. \\
\hline & $(1,55)$ & & & & & & & & \\
\hline
\end{tabular}

${ }^{\mathrm{a}}$ All $\mathrm{mAb}$ were tested at $0.231 \mathrm{mg} / \mathrm{ml}$ and fed with infected blood meal at the same time.

${ }^{\mathrm{b}}$ Arithmetic mean (range) of oocysts per mosquito midgut.

'Per cent inhibition of mean oocyst intensity (PIm[o]) and the $95 \%$ confidence interval $(95 \% \mathrm{Cl})$.

${ }^{d}$ Two-sided $p$-values for testing whether PIm[o] is significantly different from 0 .

eNumber of mosquitoes without any oocysts/number of mosquitoes examined.

${ }^{f}$ Per cent inhibition of prevalence of mosquitoes with oocysts (PIp[o]) and the $95 \% \mathrm{Cl}$.

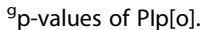

${ }^{\mathrm{h}}$ Arithmetic mean (range) of sporozoites $\left(\times 10^{3}\right)$ per mosquito. No sporozoite count in the second experiment.

'Per cent inhibition of mean sporozoite intensity (PIm[s]) and the $95 \% \mathrm{CI}$.

${ }_{\mathrm{j}}^{\mathrm{j}}$-values of PIm[s]. 
Table 5 Transmission-blocking activities of human $\mathrm{mAb}$ fed three days post-infected blood meal ${ }^{\mathrm{a}}$

\begin{tabular}{|c|c|c|c|c|c|c|c|c|}
\hline Sample & Mean ooc ${ }^{b}$ & $\operatorname{PIm}[0]^{c}$ & $p$-value ${ }^{d}$ & Mosquito $^{\mathrm{e}}$ & PIp[o] $]^{f}$ & p-value ${ }^{g}$ & Mean Spz & $\operatorname{PIm}[s]^{i}$ \\
\hline \multirow[t]{2}{*}{ MAL1C } & 15.1 & 2 & 0.97 & $1 / 20$ & -27 & 0.08 & 9.0 & 53 \\
\hline & $(0,36)$ & $(-185,65)$ & & & $(-80,3)$ & & & \\
\hline \multirow[t]{2}{*}{ MAL2A } & 11.6 & 24 & 0.64 & $1 / 20$ & -27 & 0.08 & 19.8 & -4 \\
\hline & $(0,30)$ & $(-119,74)$ & & & $(-80,3)$ & & & \\
\hline \multirow[t]{2}{*}{ Contl } & 15.3 & N/A & N/A & $5 / 20$ & N/A & N/A & 19.0 & N/A \\
\hline & $(0,44)$ & & & & & & & \\
\hline
\end{tabular}

\footnotetext{
${ }^{a}$ All $\mathrm{mAb}$ were tested at $0.231 \mathrm{mg} / \mathrm{ml}$ and fed three days post-infected blood meal.

${ }^{\mathrm{b}}$ Arithmetic mean (range) of oocysts per mosquito midgut.

${ }^{c}$ Per cent inhibition of mean oocyst intensity (PIm[o]) and the $95 \%$ confidence interval $(95 \% \mathrm{Cl})$.

${ }^{\mathrm{d}}$ Two-sided $\mathrm{p}$-values for testing whether PIm[o] is significantly different from 0 .

${ }^{\mathrm{e}}$ Number of mosquitoes without any oocysts/number of mosquitoes examined.

${ }^{f}$ Per cent inhibition of prevalence of mosquitoes with oocysts (PIp[o]) and the $95 \% \mathrm{Cl}$.

${ }_{\mathrm{g}}^{\mathrm{p}}$-values of Plp[o].

${ }^{h}$ Number of sporozoites $\left(\times 10^{3}\right)$ per mosquito calculated from a pool of salivary glands of 12 mosquitoes.

'Per cent inhibition of mean sporozoite intensity (PIm[s]).
}

\section{Discussion}

Studies have shown that anti-CS antibodies [13,29] or anti-CSPBP antibody [14] can reduce sporozoite numbers in mosquitoes. Another study has shown that the injection of CS protein or peptide into mosquitoes on day 7 or 8 post-infectious blood meal can inhibit sporozoite invasion of salivary glands [30]. It was hypothesized that anti-CS antibody induced by RTS,S/AS01 could affect oocyst formation and/or sporogony in the mosquito host. Under the conditions of this study, however, serum IgGs from RTS,S vaccinated children did not show significant inhibition in oocyst intensity, oocyst prevalence or sporozoite intensity. Similar experiments with two antiCS human monoclonal antibodies used at over 30-fold higher levels of anti-CS specific antibodies also showed no significant reduction in oocyst intensity or prevalence, and the reduction in sporozoite intensity seen in isolated experiments was not consistent.

It is likely that for an effect of anti-CS antibodies against sporogony to occur in mosquitoes, the antibodies should be present in the right anatomical compartment at sufficient concentration. That was likely the case in past studies that demonstrated the role of CS in the physiology of sporogony $[13,29]$. This study suggests that the concentration of anti-CS antibodies reaching the relevant mosquito anatomic compartment following feeding on a RTS,S-vaccinated individual is too low to produce an inhibition in sporogony. Similar negative results were obtained when evaluating the effect of human anti-sporozoite antibodies induced either by natural infection $[16,18]$ or inoculation of irradiated sporozoites [15] on the sporozoite numbers in mosquitoes. Hypothetical vaccine strategies inducing higher anti-CS antibody titres may show some inhibition, but it is unlikely considering the results of this study where anti-CS monoclonal antibodies used at high concentration failed to show any consistent inhibitory effect. Besides the antibody titre, the fine specificity could affect the results. The C-terminus and N-terminus portions of CS protein have different functions [10]. Since the RTS,S vaccine

Table 6 Transmission-blocking activities of human $\mathrm{mAb}$ fed six days post-infected blood meal ${ }^{\mathrm{a}}$

\begin{tabular}{|c|c|c|c|c|c|c|c|c|}
\hline Sample & Mean ooc ${ }^{b}$ & $\operatorname{PIm}[0]^{c}$ & p-value ${ }^{d}$ & Mosquito $^{\mathrm{e}}$ & PIp[o] ${ }^{f}$ & p-value ${ }^{g}$ & Mean Spz & $\operatorname{PIm}[s]^{i}$ \\
\hline \multirow[t]{2}{*}{$\overline{M A L 1 C}$} & 48.5 & -49 & 0.44 & $2 / 20$ & 10 & 0.15 & 50.3 & -129 \\
\hline & $(0,88)$ & $(-331,49)$ & & & $(-8,30)$ & & & \\
\hline \multirow[t]{2}{*}{ MAL2A } & 42.1 & -29 & 0.61 & $0 / 20$ & 0 & 1.00 & 23.3 & -6 \\
\hline & $(20,82)$ & $(-287,54)$ & & & $(-19,16)$ & & & \\
\hline \multirow[t]{2}{*}{ Contl } & 32.6 & $\mathrm{~N} / \mathrm{A}$ & $\mathrm{N} / \mathrm{A}$ & $0 / 20$ & $\mathrm{~N} / \mathrm{A}$ & $\mathrm{N} / \mathrm{A}$ & 22.0 & $\mathrm{~N} / \mathrm{A}$ \\
\hline & $(11,64)$ & & & & & & & \\
\hline
\end{tabular}

\footnotetext{
${ }^{\mathrm{a}}$ All $\mathrm{mAb}$ were tested at $0.231 \mathrm{mg} / \mathrm{ml}$ and fed six days post-infected blood meal.

${ }^{\mathrm{b}}$ Arithmetic mean (range) of oocysts per mosquito midgut.

${ }^{c}$ Per cent inhibition of mean oocyst intensity (PIm[o]) and the $95 \%$ confidence interval $(95 \% \mathrm{Cl})$.

${ }^{\mathrm{d}}$ Two-sided $\mathrm{p}$-values for testing whether PIm[o] is significantly different from 0 .

${ }^{\mathrm{e}}$ Number of mosquitoes without any oocysts/number of mosquitoes examined.

f Per cent inhibition of prevalence of mosquitoes with oocysts (PIp[o]) and the $95 \% \mathrm{Cl}$.

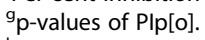

${ }^{h}$ Number of sporozoites $\left(\times 10^{3}\right)$ per mosquito calculated from a pool of salivary glands of 12 mosquitoes.

i Per cent inhibition of mean sporozoite intensity (PIm[s]).
} 
antigen does not include the N-terminal portion of CS, it was not possible to evaluate the effect of antibodies targeting the $\mathrm{N}$-terminus of the protein in this study.

An alternative explanation of the negative results in this study might be linked to inherent variability in the labourintensive biological assay, with highly variable numbers of oocysts and sporozoites within the same COM in the same feeding experiment (see [21] for discussion of this variability with respect to the oocyst counts). Indeed, the estimates of PIm[o] and PIm[s] had large 95\% CIs. Other studies were also affected by this variability; $75 \%$ inhibition in $\operatorname{PIm}[\mathrm{s}]$ did not reach significance $(\mathrm{p}=0.06)$ in one study [31], and 90\% inhibition in PIm[s] barely attained significance $(p=0.04)$ in another study [14]. While it would have been ideal to perform the study with more samples (e.g., test individual serum samples, instead of 6 pools) and repeat the assays many times to overcome the variability, the volumes of test materials which were available for this study were limited. In order to reduce the impact of the high variability in oocyte and sporozoite numbers, the anti-CS IgGs and control IgGs were also compared as groups. This analysis also failed to show any inhibition of sporogony.

A possible experimental limitation relates to the fact that the numbers of oocysts and sporozoites per mosquito are considerably higher in the SMFA than seen in natural infections in field-caught mosquitoes. Experiments with lower infection levels are complicated by the increased likelihood of mosquitoes in the control groups having no oocysts/sporozoites. Although unlikely in view of the results of this study, an effect under conditions of lower infectivity cannot be ruled out.

Another possible factor determining the inhibitory effect of ingested antibodies on sporogony is the timing of ingestion relative to the stage of the parasite life cycle. In past studies, researchers used different days, ranging from five to eleven days after the initial feed, to evaluate the effect [12,14-18,31]. In this study, the mosquitoes were challenged with the test antibodies three or six days after the initial gametocyte feed in the serial-feed experiments. Further investigations would be required to evaluate the effect of delaying a second feed. Relevance to mosquito behaviour in nature would need to be considered,

\section{Conclusions}

Previous studies have clearly shown that CS protein has a significant role in sporozoite development in mosquitoes. Keeping in mind the limitations of the experimental approach (oocyst and sporozoite count variability, limited sample volume available for testing, high infectivity compared to nature, serial feeding to day 6 only), this study does not support the concept that antibodies induced by the RTS,S/AS01 vaccine in human noticeably reduce malaria transmission by blocking sporozoite development or salivary gland invasion in mosquitoes when taken up during feeding. Whether RTS,S/AS01 vaccine may reduce transmission in a population through the ability of preerythrocytic immunity to prevent new infections remains to be evaluated.

\section{Abbreviations}

CS: Circumsporozoite; CSPBP: Circumsporozoite protein-binding protein; SMFA: Standard membrane feeding assay; Cl: Confidence interval; mAb: Monoclonal antibody; EU: ELISA units; PBS: Phosphate buffered saline; PIm[o]: \% inhibition of mean oocyst intensity; Plp[o]: \% inhibition of oocyst prevalence; PIm[s]: \% inhibition of mean sporozoite intensity; COM: Container of mosquitoes.

\section{Competing interests}

Johan Vekemans and Erik Jongert are GSK employees and own GSK shares.

\section{Authors' contributions}

$\mathrm{KM}, \mathrm{EJ}, \mathrm{CAL}$ and $\mathrm{JV}$ designed the study and drafted the manuscript. JPL and CJD designed the study and conducted the human RTS,S vaccine trial. KM, $\mathrm{BD}$ and $\mathrm{LZ}$ performed the study. MPF analysed the data and drafted the manuscript. All authors read and approved the final manuscript.

\section{Acknowledgements}

We are very grateful to the children who participated in the Phase 2 study. We thank Andre Laughinghouse, Kevin Lee, Tovi Lehmann and Robert Gwadz for insectary support, and Ababacar Diouf and Samuel Moretz for helping with the data acquisition. Lorenz von Seidlein was a lead investigator of the Phase 2 study and led the field clinical work. This study was supported in part by the PATH Malaria Vaccine Initiative and also by the Intramural Research Program of the National Institute of Allergy and Infectious Diseases, NIH.

\section{Author details}

${ }^{1}$ Laboratory of Malaria and Vector Research, National Institute of Allergy and Infectious Diseases, National Institutes of Health, 12735 Twinbrook Parkway, Rockville, MD 20852, USA. ${ }^{2}$ GlaxoSmithKline Vaccines, Wavre, Belgium. ${ }^{3}$ National Institute for Medical Research, Tanga Centre, Korogwe site, Tanga, Tanzania. ${ }^{4}$ Center for Medical Parasitology, Department of Medical Microbiology and Immunology, University of Copenhagen, Copenhagen, Denmark. ${ }^{5}$ Faculty of Infectious and Tropical Diseases, London School of Hygiene and Tropical Medicine, London, UK. 'Biostatistics Research Branch, National Institute of Allergy and Infectious Diseases, National Institutes of Health, Bethesda, USA.

Received: 9 May 2014 Accepted: 3 July 2014

Published: 9 July 2014

\section{References}

1. Targett GA, Greenwood BM: Malaria vaccines and their potential role in the elimination of malaria. Malar J 2008, 7(Suppl 1):S10.

2. Dinglasan RR, Kalume DE, Kanzok SM, Ghosh AK, Muratova O, Pandey A, Jacobs-Lorena M: Disruption of Plasmodium falciparum development by antibodies against a conserved mosquito midgut antigen. Proc Natl Acad Sci U S A 2007, 104:13461-13466.

3. Raz A, Dinparast Djadid N, Zakeri S: Molecular characterization of the Carboxypeptidase B1 of Anopheles stephensi and its evaluation as a target for transmission-blocking vaccine (TBV). Infect Immun 2013, 81:2206-2216.

4. Lavazec C, Boudin C, Lacroix R, Bonnet S, Diop A, Thiberge S, Boisson B, Tahar R, Bourgouin C: Carboxypeptidases B of Anopheles gambiae as targets for a Plasmodium falciparum transmission-blocking vaccine. Infect Immun 2007, 75:1635-1642.

5. Olotu A, Fegan G, Wambua J, Nyangweso G, Awuondo KO, Leach A, Lievens M, Leboulleux D, Njuguna P, Peshu N, March K, Bejon P: Four-year efficacy of RTS, S/AS01E and its interaction with malaria exposure. N Engl J Med 2013, 368:1111-1120.

6. Aikawa M, Atkinson CT, Beaudoin LM, Sedegah M, Charoenvit Y, Beaudoin R: Localization of CS and non-CS antigens in the sporogonic stages of Plasmodium yoelii. Bull World Health Organ 1990, 68(Suppl):165-171. 
7. Nagasawa H, Procell PM, Atkinson CT, Campbell GH, Collins WE, Aikawa M: Localization of circumsporozoite protein of Plasmodium ovale in midgut oocysts. Infect Immun 1987, 55:2928-2932.

8. Posthuma G, Meis JF, Verhave JP, Hollingdale MR, Ponnudurai T, Meuwissen $\mathrm{JH}$, Geuze HJ: Immunogold localization of circumsporozoite protein of the malaria parasite Plasmodium falciparum during sporogony in Anopheles stephensi midguts. Eur J Cell Biol 1988, 46:18-24.

9. Kappe SH, Kaiser K, Matuschewski K: The Plasmodium sporozoite journey: a rite of passage. Trends Parasitol 2003, 19:135-143.

10. Coppi A, Natarajan R, Pradel G, Bennett BL, James ER, Roggero MA, Corradin $G$, Persson C, Tewari R, Sinnis P: The malaria circumsporozoite protein has two functional domains, each with distinct roles as sporozoites journey from mosquito to mammalian host. J Exp Med 2011, 208:341-356.

11. Brooks A, Briet OJ, Hardy D, Steketee R, Smith TA: Simulated impact of RTS, S/AS01 vaccination programs in the context of changing malaria transmission. PLoS One 2012, 7:e32587.

12. Vaughan JA, Do Rosario V, Leland P, Adjepong A, Light J, Woollett GR, Hollingdale MR, Azad AF: Plasmodium falciparum: ingested anti-sporozoite antibodies affect sporogony in Anopheles stephensi mosquitoes. Exp Parasitol 1988, 66:171-182.

13. Fang W, Vega-Rodriguez J, Ghosh AK, Jacobs-Lorena M, Kang A, St Leger RJ: Development of transgenic fungi that kill human malaria parasites in mosquitoes. Science 2011, 331:1074-1077.

14. Wang J, Zhang Y, Zhao YO, Li MW, Zhang L, Dragovic S, Abraham NM, Fikrig E: Anopheles gambiae circumsporozoite-protein binding-protein facilitates Plasmodium infection of mosquito salivary glands. J Infect Dis 2013, 208:1161-1169.

15. Davis JR, Beier MS, Beier JC, Pumpuni CB, Edelman R, Herrington DA, Clyde DF: Effects of ingested human anti-sporozoite sera on Plasmodium falciparum sporogony in Anopheles stephensi. Am J Trop Med Hyg 1993 49:174-180.

16. Beier JC, Oster CN, Koros JK, Onyango FK, Githeko AK, Rowton E, Koech DK, Roberts CR: Effect of human circumsporozoite antibodies in Plasmodiuminfected Anopheles (Diptera: Culicidae). J Med Entomol 1989, 26:547-553.

17. do Rosario VE, Appiah A, Vaughan JA, Hollingdale MR: Plasmodium falciparum: administration of anti-sporozoite antibodies during sporogony results in production of sporozoites which are not neutralized by human anticircumsporozoite protein vaccine sera. Trans R Soc Trop Med Hyg 1989, 83:305-307

18. Ponnudurai T, Lensen AH, van Gemert GJ, Bensink MP, Bolmer M, Meuwissen $\mathrm{JH}$ : Sporozoite load of mosquitoes infected with Plasmodium falciparum. Trans R Soc Trop Med Hyg 1989, 83:67-70.

19. Bejon P, Lusingu J, Olotu A, Leach A, Lievens M, Vekemans J, Mshamu S, Lang T, Gould J, Dubois MC, Demoitié MA, Stallaert JF, Vansadia P, Carter T, Njuguna P, Awuondo KO, Malabeja A, Abdul O, Gesase S, Mturi N, Drakeley CJ, Savarese B, Villafana T, Ballou WR, Cohen J, Riley EM, Lemnge MM, Marsh $K$, von Seidlein L: Efficacy of RTS, S/AS01E vaccine against malaria in children 5 to 17 months of age. N Engl J Med 2008, 359:2521-2532.

20. Clement F, Dewar V, Van Braeckel E, Desombere I, Dewerchin M, Swysen C, Demoitie MA, Jongert E, Cohen J, Leroux-Roels G, Cambron P: Validation of an enzyme-linked immunosorbent assay for the quantification of human IgG directed against the repeat region of the circumsporozoite protein of the parasite Plasmodium falciparum. Malaria J 2012, 11:384.

21. Miura K, Deng B, Tullo G, Diouf A, Moretz SE, Locke E, Morin M, Fay MP, Long CA: Qualification of standard membrane-feeding assay with Plasmodium falciparum malaria and potential improvements for future assays. PLoS One 2013, 8:e57909.

22. Churcher TS, Blagborough AM, Delves M, Ramakrishnan C, Kapulu MC, Williams AR, Biswas S, Da DF, Cohuet A, Sinden RE: Measuring the blockade of malaria transmission - An analysis of the standard membrane feeding assay. Int J Parasitol 2012, 42:1037-1044.

23. van der Kolk M, De Vlas SJ, Saul A, van de Vegte-Bolmer M, Eling WM, Sauerwein RW: Evaluation of the standard membrane feeding assay (SMFA) for the determination of malaria transmission-reducing activity using empirical data. Parasitology 2005, 130:13-22.

24. Vaughan JA, Noden BH, Beier JC: Population dynamics of Plasmodium falciparum sporogony in laboratory-infected Anopheles gambiae. J Parasitol 1992, 78:716-724.

25. Miettinen O, Nurminen M: Comparative analysis of two rates. Stat Med $1985,4: 213-226$
26. Viechtbauer $\mathrm{W}$ : Conducting meta-analyses in $\mathrm{R}$ with the metafor package. J Stat Softw 2010, 36:1-48.

27. Aponte JJ, Aide P, Renom M, Mandomando I, Bassat Q, Sacarlal J, Manaca MN, Lafuente S, Barbosa A, Leach A, Lievens M, Vekemans J, Sigauque B, Dubois MC, Demoitie MA, Sillman M, Savarese B, McNeil JG, Macete E, Ballou WR, Cohen J, Alonso PL: Safety of the RTS, S/AS02D candidate malaria vaccine in infants living in a highly endemic area of Mozambique: a double blind randomised controlled phase I/Ilb trial. Lancet 2007, 370:1543-1551.

28. Lell B, Agnandji S, von Glasenapp I, Haertle S, Oyakhiromen S, Issifou S, Vekemans J, Leach A, Lievens M, Dubois MC, Demoitie MA, Carter T, Villafana T, Ballou WR, Cohen J, Kremsner PG: A randomized trial assessing the safety and immunogenicity of ASO1 and AS02 adjuvanted RTS,S malaria vaccine candidates in children in Gabon. PLOS One 2009, 4:e7611.

29. de Lara CM, Coleman J, Beerntsen BT, Myles KM, Olson KE, Rocha E, Krettli AU, James AA: Virus-expressed, recombinant single-chain antibody blocks sporozoite infection of salivary glands in Plasmodium gallinaceum-infected Aedes aegypti. Am J Trop Med Hyg 2000, 62:427-433.

30. Myung JM, Marshall $P$, Sinnis P: The Plasmodium circumsporozoite protein is involved in mosquito salivary gland invasion by sporozoites. Mol Biochem Parasitol 2004, 133:53-59.

31. Brennan JD, Kent M, Dhar R, Fujioka H, Kumar N: Anopheles gambiae salivary gland proteins as putative targets for blocking transmission of malaria parasites. Proc Natl Acad Sci U S A 2000, 97:13859-13864.

doi:10.1186/1475-2875-13-263

Cite this article as: Miura et al.: Effect of ingested human antibodies induced by RTS, S/AS01 malaria vaccination in children on Plasmodium falciparum oocyst formation and sporogony in mosquitoes. Malaria Journal 2014 13:263.

\section{Submit your next manuscript to BioMed Central and take full advantage of:}

- Convenient online submission

- Thorough peer review

- No space constraints or color figure charges

- Immediate publication on acceptance

- Inclusion in PubMed, CAS, Scopus and Google Scholar

- Research which is freely available for redistribution 